\title{
The financial effects of uniform and mixed corporate social performance
}

Article

Accepted Version

Oikonomou, I., Brooks, C. and Pavelin, S. (2014) The financial effects of uniform and mixed corporate social performance. Journal of Management Studies, 51 (6). pp. 898-925. ISSN 1467-6486 doi: https://doi.org/10.1111/joms.12064 Available at https://centaur.reading.ac.uk/34083/

It is advisable to refer to the publisher's version if you intend to cite from the work. See Guidance on citing.

Published version at: http://onlinelibrary.wiley.com/doi/10.1111/joms.12064/abstract

To link to this article DOI: http://dx.doi.org/10.1111/joms.12064

Publisher: Wiley-Blackwell

All outputs in CentAUR are protected by Intellectual Property Rights law, including copyright law. Copyright and IPR is retained by the creators or other copyright holders. Terms and conditions for use of this material are defined in the End User Agreement.

\section{www.reading.ac.uk/centaur}

\section{CentAUR}

Central Archive at the University of Reading

Reading's research outputs online 
Notice: This is the authors' accepted manuscript of an article published in the Journal of Management Studies, Volume 51, Issue 6, pages 898-925, September 2014. The definitive version is available at DOI: 10.1111 joms. 12064 


\title{
The financial effects of uniform and mixed corporate social performance
}

\author{
Ioannis Oikonomou \\ ICMA Centre, Henley Business School, \\ University of Reading, UK
}

Chris Brooks

ICMA Centre, Henley Business School,

University of Reading, UK

Stephen Pavelin

Centre for Business, Organisations and Society, School of Management, University of Bath, UK 


\title{
The financial effects of uniform and mixed
}

\section{corporate social performance}

\begin{abstract}
Firms typically present a mixed picture of corporate social performance (CSP), with positive and negative indicators exhibited by the same firm. Thus, stakeholders' judgements of corporate social responsibility (CSR) typically evaluate positives in the context of negatives, and vice versa. Building on social judgement theory, we present two alternative accounts of how stakeholders respond to such complexity, which provide differing implications for the financial effects of CSP: reciprocal dampening and rewarding uniformity. Echoing notable findings on strategic consistency, our US panel study finds that firms that exhibit uniformly positive or uniformly negative indicators in particular dimensions of CSP outperform firms that exhibit a mixed picture of positives and negatives - which supports the notion that stakeholders' judgements of CSR reward uniformity.
\end{abstract}

Keywords: Corporate social responsibility; Corporate social performance; Corporate reputation; Social judgement theory; Strategic consistency 


\section{INTRODUCTION}

While our understanding of the of a firm's social responsibilities is underpinned by normative arguments, the nature of the relationship between corporate social performance (CSP) and corporate financial performance (CFP) provides key, additional insights towards our understanding of the strategic implications of social and environmental issues. By refining our understanding of the business case for corporate social responsibility (CSR), we more perfectly identify the boundaries on firms' private incentives to invest in CSR, and so usefully inform both corporate management and regulatory practice. While there is much insightful prior scholarship that addresses CSR, and particularly the financial returns to CSP (Tang, Hull and Rothenberg, 2012; Arya and Zhang, 2009; Margolis and Walsh, 2003; Griffin and Mahon, 1997; Wood and Jones, 1995; McWilliams and Siegel, 2000; Waddock and Graves, 1997), a key component of the business case - as it is commonly understood within the Instrumental Stakeholder Theory paradigm - has been largely overlooked. Specifically, and in contrast to the detailed discussion of the implications for managerial decision-making of stakeholders' concerns for social and environmental issues (e.g. Mitchell, Agle and Wood, 1997; Porter and Kramer, 2002), there has been relatively little consideration of the manner in which stakeholders judge CSR from available information, and how these judgements affect their behaviour towards firms. We draw upon insights from social judgement theory to address this lacuna and propose that, in the context of stakeholder judgements of CSR, there is a key distinction between information sets that offer a uniform picture of either responsible or irresponsible conduct and information sets that instead offer stakeholders a mixed picture.

Our focus upon the firm-level distinction between uniform CSP - such that a firm exhibits only positive or only negative indicators of CSP - and mixed CSP - such that a firm exhibits both positive and negative indicators - is somewhat redolent of the prior literature on strategic consistency (e.g. Lamberg, Tikkanen, Nokelainen and Suur-Inkeroinen, 2009; Nath and 
Sudharshan, 1994). Though variously defined, to include both inter-temporal and crossorganizational consistency, the concept reflects an imperative to maintain coherence in the midst of large, diverse and complex businesses and competitive environments. Numerous of these studies have investigated financial effects by testing the degree to which the expectable benefits of strategic consistency - for example, in R\&D across business units (Harrison, Hall and Nargundkar, 1993) - are realised (e.g. Joshi, Kathuria and Porth, 2003; Kathuria, Joshi and Porth, 2007; Baier, Hartmann and Moser, 2008). Regarding the manner in which a firm addresses social and environmental issues, uniform CSP is an apparent exemplar of strategic consistency, wherein consonant issues are addressed in a manner that yields no countervailing evidence; instead, CSP composed of a mix of positive and negative indicators is more likely to result from an inconsistency in how such issues are addressed across different business units (say, subsidiaries in different countries) or business functions (say, Human Resources and Procurement).

It is commonplace for firms to exhibit both positive and negative indicators of CSP say, a firm makes sizable donations to wildlife charities but is also associated with environmental degradation; or, a firm is an exemplary equal opportunity employer but also tolerates child labour in its supply chain. In such cases, stakeholders must weigh good against bad in order to form a judgement of whether the firm is socially responsible - which raises the question: How do stakeholders judge CSR in light of such a mixed picture, and condition their behaviour accordingly? More specifically: Does the good offset the bad, or is misconduct viewed as diagnostic of irresponsibility, no matter how many accompanying positive indicators? Are negative indicators more dimly viewed if accompanied by evidence that the company has otherwise simultaneously sought to demonstrate - erroneously and cynically it may now seem some creditable degree of CSR? 
Only a few prior studies investigate the manner in which stakeholders' judgements of CSP balance off positives and negatives, and none evaluate the resulting financial effects. For example, Pomering and Dolnicar (2009) study consumer awareness of CSR activities and point out that "better context may amount to little if claimed CSR initiatives are perceived as inconsistent with other facets of the business that reflect its values and ethics" (p.285). Vanhamme and Grobben (2009) study the ways in which CSR can help counter the effects that negative publicity (caused by some sort of firm transgression) has on corporate reputation. They also highlight the role of motivation in this process, along with that of CSR history. In addition, Yoon et al. (2006) provide evidence which supports the notion that CSR activities may have a beneficial, neutral or negative effect on a company's image depending on whether the sincerity of its motives in relation to these activities is determined to be genuine, ambiguous or insincere, respectively. Lastly, perhaps the most thematically related study of all comes from Kotchen and Moon (2007), who claim that firms engage in CSR simply to offset the impact of their negative social and environmental actions. Their empirical analysis generally supports this assertion, especially when looking at the community relations and environmental dimensions of CSP.

Here, we investigate the relationship between CSP and CFP among large US firms in order to infer key features of the influence on stakeholder behaviour that is exerted by CSP information, and particularly how the behaviour of these stakeholders is differently influenced by uniform and mixed evidence of CSP. Many previous studies of the CSP-CFP link have overlooked the potential importance of the composition of CSP across positives and negatives by ruling out such effects by assumption. While an emergent recent trend for the financial effects of positive and negative indicators to be separately estimated, we wish in this study to broaden the purview to permit the financial effects of a firm's CSP positives to differ depending upon whether or not they are accompanied by negative indicators, and the financial effects of a firm's CSP negatives to differ depending upon whether or not they are accompanied by positive 
indicators. A number of recent studies that focus upon either corporate charitable giving or aggregate CSP (which combines positive and negative indicators into a net score) have estimated a U-shaped relationship between CSP and CFP, such that better financial returns are associated with the highest and lowest levels of CSP; e.g. Barnett and Salomon (2012) and Brammer and Millington (2008). Of prior studies, these are the most closely related to ours, and in our concluding remarks we will discuss our findings in the context of the evidence previously provided on a U-shaped CSP-CFP link.

By developing and testing hypotheses that draw upon arguments from social judgement theory regarding cue diagnosticity within reputational assessments of corporate character, this paper makes a number of contributions to the literature. By providing insights into the manner in which stakeholders judge CSP and condition behaviour accordingly - as manifested in effects on CFP - we provide new lessons for managerial practice of CSR strategy. First, these lessons relate to both the existence of, and limits on, the business case for CSR - and specifically the critical importance of understanding how any investments in creditable CSP are viewed in the context of other indicators of a firm's social impacts. Illuminating the manner in which a firm's mixed picture of CSP is viewed in-the-round is potentially instructive for managers seeking to formulate a CSR strategy that not only augments a firm's social contributions but also improves financial performance. Second, the study addresses the claim that investments in CSP can offset reputational harm from negative indicators of CSP (e.g. Brammer, Pavelin and Porter, 2009), by asking: 'How does positive CSP alter the financial effect of negative CSP?' and 'How does negative CSP alter the financial effect of positive CSP?' To put it differently, if a company does 'good' when it also does something 'bad', will it also do 'well' (or at least better) in financial terms? Thirdly, by contributing to the literature on the CSP-CFP link that empirically focuses upon stock-market-based measures of CFP (e.g.: Barnett and Salomon, 2006; 2012; Oikonomou, Brooks and Pavelin, 2012; Brammer, Brooks and Pavelin, 2006; 2009), this study provides 
lessons for the practice of socially responsible investment (SRI), and particularly the social criteria and screens that are most appropriate (and likely to bring the highest returns) when many commonly-held stocks are associated with firms that exhibit both positive and negative indications of CSP.

The remainder of this paper is structured as follows: Section 2 provides the theoretical background and the development of hypotheses. The characteristics of the dataset used and the details of the method applied are discussed in Section 3. Section 4 presents the results of the various analyses and the robustness tests that have been performed. Section 5 draws conclusions and suggests lessons for practice.

\section{THEORETICAL BACKGROUND AND HYPOTHESES DEVELOPMENT}

The starting point for our argument is that stakeholders - those who affect or are affected by a firm's activities (Freeman, 1984) - have preferences that cause (at least some of) them to (at least to some degree) favour relationships with firms that they judge to be socially responsible, i.e. consumers are more willing to pay for such firms' products; employees are more willing to work for such companies, investors are more willing to own those firms' shares, and so on. In this way, stakeholders care about CSR in a manner that potentially translates into their behaviour within the stakeholder-firm relationship (Mitchell et al., 1997). As CFP is determined by the nature of a company's interactions with stakeholders, then to the extent that stakeholders' behaviours towards firms are affected by perceived CSR, financial performance is affected by stakeholders' judgments regarding social responsibility (Clarkson, 1995; Jones, 1995).

CSP is a concept with many facets and has been commonly defined as a firm's "configuration of principles of social responsibility, processes of social responsiveness, and policies, programs, and observable outcomes as they relate to the firm's societal relationships" (Wood, 1991, p.693). CSP is also multidimensional. It spans numerous social and environmental 
issues - from carbon emissions to equal opportunities in hiring; from community projects to product safety and so on. Furthermore, for each type of issue, it encompasses both the potential for firms to demonstrate strength - e.g. support charities that restore aquatic environments and facilitate employee volunteering - or expose weakness - e.g. receive regulatory sanctions for excessive pollution or sustain child labour in supply chains. It is therefore possible for a single firm to offer a complex and conflicting picture regarding its CSP. Not only might a firm exhibit strengths in some dimensions of CSP and weaknesses in others, it might also show both positive and negative indicators pertaining to the same dimension of CSP, e.g. environmental performance. Indeed, commonly-cited metrics (including those employed in this study) suggest that it is common for large firms to offer just this kind of mixed picture to its stakeholders. Therefore, stakeholders that wish to behave towards a firm in a manner that is contingent upon their perception of that firm's CSP must commonly form a view that takes into account the existence of conflicting indicators.

To discuss the manner in which CSR is judged in light of mixed indications, we must consider how stakeholders regard firms and react to their perceptions of responsibility and irresponsibility. Such judgements - which focus upon corporate character rather than simply performance indicators of quality or efficiency - imply assessments of a firm's goals, preferences and values (Love and Kraatz, 2009), and "are used by stakeholders to make behavioural predictions and determine whether the target organization's goals and values are congruent with their own” (Mishina, Block and Mannor, 2012, p.461).

Drawing upon social judgement theory from social psychology, Mishina et al. (2012) discuss the prospect of conflicting indicators in the context of socio-cognitive processes that shape judgements of corporate character, and particularly stakeholder judgements of social responsibility and irresponsibility. In discussing the manner in which one piece of relevant information - or cue - is interpreted in light of other similarly relevant pieces of information, 
Mishina et al. employ the concept of cue diagnosticity. This concept reflects the processes through which the meaning of each cue is interpreted and combined with others to form an overall assessment. Specifically, cue diagnosticity describes the tendency for some cues to be given greater weight than others, and one should expect the diagnostic weight granted to a particular cue to systematically vary with the type of assessment to be made and also depend upon whether the cue is positive or negative.

While positive cues relating to a firm's capabilities are viewed as strongly diagnostic - as good performance is likely to be viewed as compelling evidence that a firm has the capability to perform well, even if other indications point to poor performance - this is reversed for character judgements. Mishina et al. argue that:

\footnotetext{
"Negative cues are viewed as more diagnostic and thus given greater weight than positive cues....

This is because positive cues, such as good behavior, may merely be an indication of conformance with societal expectations and norms, thereby conveying relatively ambiguous or equivocal information about underlying attributes... As a result, positive cues may be considered the baseline - what is societally expected, making negative cues particularly salient as a deviation from the norm and seemingly much more diagnostic of the true underlying character of the target being evaluated."
}

Mishina et al. (2012, p. 462-3)

This implies that, even in the presence of positive indicators, negative indicators are greatly influential on character judgements because they are viewed as highly diagnostic of a firm's true character because positive indicators can be dismissed as resulting from mere compliance with socially expected norms. That said, consistent with some findings from social psychology (Bromberg and Fine, 2002), there may be a tendency for firms that enjoy positive character judgements among stakeholders (due to a preponderance of positive indicators) to be inured from the harmful judgements that might otherwise result from negative indicators. However, Mishina et al. argue that such an effect should be expected to apply to only those most favourably-viewed firms and in the context of only weak indications of misconduct (Hollander, 
1958). This point echoes that made by Godfrey (2005) that, in the face of an ambiguous event that may or may not imply socially irresponsible conduct on the part of a firm - such as an oil spill or airplane crash - positive character evidence (e.g. creditable levels of philanthropy) may be employed by stakeholders to determine whether the firm should be dimly viewed or given the benefit of the doubt.

Furthermore, regarding the weight stakeholders place upon positive indicators, Mishina et al. add that:

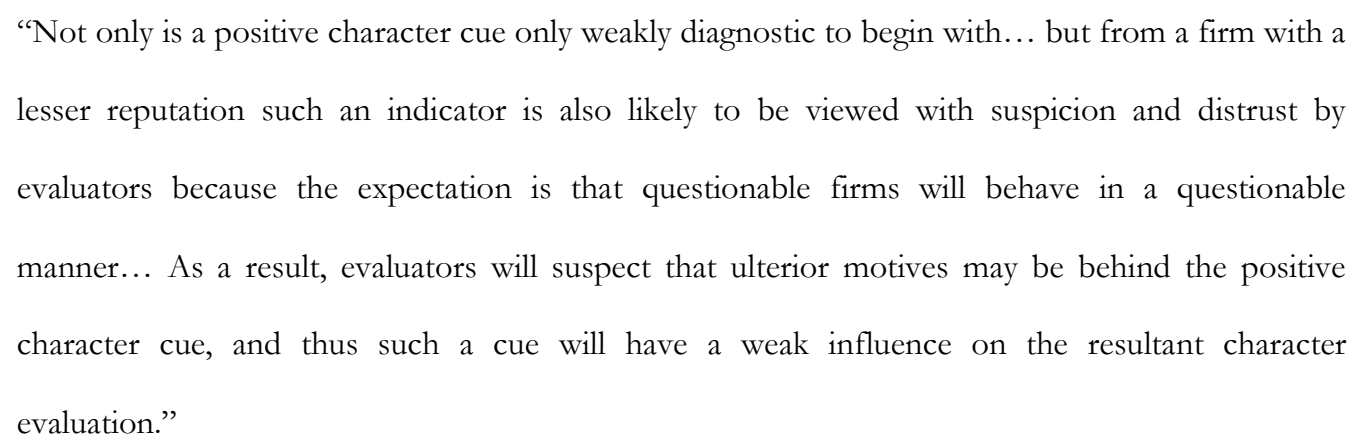

Mishina et al. (2012, p. 466)

This point - that in the presence of evidence to the contrary, a positive indicator is ineffective in demonstrating creditable CSR in the minds of stakeholders, as it is taken to be cynically motivated and inconsistent with the firm's true character - is taken further by Godfrey (2005). He argues that efforts to demonstrate CSR that stakeholders judge to be motivated not from a genuine regard for social welfare, but rather from a desire to garner favour from stakeholders, result in negative, rather than only weakly positive, reputational consequences. According to Godfrey, "imputations of motivation turn on one simple question: Does the philanthropic activity at hand represent a genuine manifestation of the firm's underlying intentions, vision, and character, or is the activity designed to ingratiate the firm among the impacted community?... [where] ingratiation is illicit and morally negative because it involves deception; honorable acts belie dishonorable motives, and the goal of the ingratiator is to be seen as good without actually being good." (p. 784). Here then, a firm that exhibits negative indicators of CSP, may elicit stakeholder inferences of irresponsibility that would lead stakeholders to take a 
dim view of even that firm's positive CSP indicators - because stakeholders view the negatives as diagnostic of corporate character and therefore view positive indicators as reflective not of a genuine regard for social welfare, but rather as attempts to present a misleading impression of the firm and its values.

We will next offer a novel application of the preceding arguments to the relationship between CSP and CSR judgements, which focuses upon the distinction between uniform CSP (which is found where a firm exhibits only positive, or only negative, indicators) and mixed CSP (which is found where a firm exhibits both positive and negative indicators). This application, which synthesises the arguments of Mishina et al. (2012) and Godfrey (2005), provides a basis from which we derive two sets of alternative hypotheses regarding the different financial impacts of uniform and mixed CSP. To begin, we will offer two alternative characterisations of how stakeholders perceive indications of mixed CSP. According to the first, stakeholders' responses to CSP are such that the positive financial effects of positive indicators are weakened by the coincident presence of negative CSP indicators, and the negative financial effects of negative indicators are weakened by the coincident presence of positive CSP indicators - we refer to this as reciprocal dampening. According to the second, stakeholders' responses to CSP indicators are again influenced by the composition of CSP across positives and negatives, but in a different manner. In this case, stakeholders tend to view negative indicators as strongly diagnostic of irresponsible character, even if accompanied by positive indicators. From this, results the prospect that the worst financial returns are associated with a mix of positive and negative CSP indicators, with better financial returns associated with uniform CSP, whether all indicators are positive or all are negative - we refer to this as rewarding uniformity. 


\subsection{Reciprocal dampening}

According to Mishina et al. (2012), we should expect stakeholders to view positive CSP indicators in light of negative CSP indicators, and vice versa. Furthermore, as judgements of social responsibility and irresponsibility relate to corporate character, we should expect the cue diagnosticity of negative indicators to be stronger than that of positive indicators. In the context of a mix of positives and negatives, we should expect positive cues to exert a relatively weak influence on stakeholder assessments of CSR, compared to negative cues. In order to translate these expectations about stakeholder judgements into hypotheses regarding CFP, two further points must be made. First, and as outlined above, we assume that stakeholder behaviour is significantly contingent upon such judgements, such that stakeholders are more willing to maintain a relationship with firms that they judge to be socially responsible rather than irresponsible. This provides a mechanism through which these CSR judgements affect CFP.

There are, of course, various types of stakeholder relationships - e.g. customer, shareholder and employee - which are differently contingent upon a host of firm characteristics. For example, the maintenance of a customer relationship would be expected to be more strongly contingent upon product quality, and less strongly contingent upon working conditions, than an employee relationship. However, there is empirical support for an apparent influence of CSR judgements on stakeholder behaviour across numerous, otherwise disparate stakeholder roles see, for example: Sen and Bhattacharya (2001) for evidence on customers, Cox, Brammer and Millington (2004) for evidence on shareholders, and Brammer, Millington and Rayton (2007) for evidence on employees. Our assumption requires that, for a sufficiently large proportion of stakeholder relationships that materially impact CFP, stakeholder behaviour sufficiently strongly favours relationships with firms that they perceive to be socially responsible rather than irresponsible. 
Second, we should acknowledge the tendency for positive CSP indicators to result from costs incurred - e.g. charitable donations paid, environmental projects funded, and so on - but negative CSP indicators to result from potential costs saved - philanthropic opportunities foregone, economically cheap but environmentally-damaging waste disposal, and so on. Of course, as has been well-documented in academic writing as well as news media, there are numerous notable examples of companies spending large sums on CSP-related initiatives only to be associated with high-profile scandals that promote assessments of irresponsibility - e.g. firms that donate voluminously to education charities that are pilloried for their working conditions, or that hold a firm line against animal testing but that are criticised by human rights groups for their supply chain practices. The point here is not that one should expect firms to be more positively (negatively) perceived the greater (smaller) are the CSP-related costs they incur - indeed, this point does not relate to CSR judgements at all, but rather to CSP. Instead, we wish to note a tendency for CSP-related initiatives to be commonly (though not exclusively; Rao and Holt, 2005) associated with some level of economic costs. If so, we should expect some tendency for the private economic costs associated with CSP to vary with CSP, and across sets of firms that exhibit uniformly positive CSP indicators, uniformly negative CSP indicators and a mixed picture, respectively.

For the moment, let us assume that the cue diagnosticity of positive cues - even in the presence of negative cues - is, while weaker than that of negative cues, sufficiently strong to outweigh the CFP effects of the economic costs of positive impacts on CSP. Given the superior diagnosticity of negative cues, stakeholder character judgements from mixed evidence are more similar to those from uniformly negative indicators than those from uniformly positive indicators. However, here we assume that the positive cues carry enough weight with stakeholders to ensure that, for those firms that exhibit mixed CSP indicators, there is a financial return on CSP (from the beneficial effects on stakeholder behaviour) that more than reimburses 
any CSP-related costs incurred. This implies that the best financial returns are associated with uniformly positive CSP, the worst financial returns are associated with uniformly negative CSP, and intermediate returns are associated with mixed indicators. Consistent with this, we propose the following hypotheses:

Hypothesis 1: The financial returns associated with uniformly positive CSP indicators are better than those associated with uniformly negative CSP indicators.

Hypothesis 2: The financial returns associated with a mix of positive and negative CSP indicators are worse than those associated with uniformly positive indicators and better than those associated with uniformly negative CSP indicators.

\subsection{Rewarding uniformity}

Here we consider the prospect that, in taking a view of a firm's CSP, stakeholders might make the least favourable judgments of firms that exhibit a mix of positives and negatives. For this, we require a change of assumptions from those adopted in the previous sub-section. Here we assume that the superior diagnosticity of negative cues is sufficiently great for stakeholder character judgements from mixed evidence to be no more (or not significantly more) positive than those from uniformly negative indicators. So, for firms that exhibit mixed CSP indicators, there is not a sufficiently large financial return on CSP to reimburse any CSP-related costs incurred. This, in contrast to the previous sub-section, implies that, while the most positive financial returns are again associated with uniformly positive CSP, the most negative financial returns are associated with mixed indicators, and intermediate returns are associated with uniformly negative CSP.

To further support this view, let us revisit the arguments forwarded by Godfrey (2005) in some further detail. His argument provides a support for the notion that stakeholder judgements 
of CSR will be more negative for firms that exhibit mixed performance than even those firms that exhibit only negative CSP indicators. Godfrey argues that stakeholders, "assess interactions between the firm and stakeholders... that reflect some degree of 'moral coloration' by individual actors, managers and leaders within the firm" and "from these morally colored activities and contexts, stakeholders impute moral values, principles and character elements that compose a moral reputation" (p.783). He proposes that an act of corporate philanthropy will positively affect such a reputational assessment only if stakeholders infer that the charitable donation is suitably motivated. Crucially, if a firm's philanthropy is judged not to be genuinely motivated, it will impact negatively on the firm's moral reputation, despite the anticipated benefits with regard to the charitable cause. As mentioned previously, this is because ingratiation is dimly-viewed. In principle, this characterization of stakeholders' reputational judgments of firms' social responsibility and irresponsibility applies not only to philanthropic acts but also to any corporate action that carries potential implications for assessments of whether a firm's decision-making is governed by a genuine regard for social welfare - as is argued by Godfrey, Merrill and Hansen (2009). Therefore, we will apply Godfrey's arguments to stakeholders' assessments of CSP in toto, and specifically to assessments in light of CSP indicators that are, in turn: uniformly positive; a mix of positives and negatives; uniformly negative.

In the first case, positive character inferences from positive CSP indicators are not undermined by negative indicators. This promotes a tendency among stakeholders to view the firm as being genuinely socially responsible as they have exhibited no tendency to mix CSR initiatives with the types of deleterious social impacts that stakeholders might view as diagnostic of a disregard for social welfare. In the second case, a mixed picture threatens just such inferences, whereby a firm that demonstrates creditable CSR in some aspects does not precipitate inferences of a responsible character because these positives are viewed in light of negatives that critically influence stakeholders' judgments. Echoing the notion of corporate 
insincerity (Yoon et al., 2006), the presence of negative indicators threatens the inference that the firm's positives in CSP are the fruit of ingratiating attempts to mitigate the reputational effects of, and/or distract attention from, its tendency (and apparent willingness) to otherwise impose harms on society. In the third case, there are negative CSP indicators and no positive indicators. While such a firm demonstrates no signals of creditable CSP - and one would expect stakeholders to take a dim view of their negative CSP indicators - they do not additionally attract inferences of ingratiation and threaten inferences of deceptive, morally negative corporate behaviour.

To reflect these arguments, we will test the following additional hypothesis:

Hypothesis 3: The financial returns associated with a mix of positive and negative CSP indicators lie below those associated with uniformly positive and uniformly negative CSP indicators.

Please note that both reciprocal dampening and rewarding uniformity predict better financial returns for uniformly positive CSP indicators compared to uniformly negative indicators - i.e. both are consistent with Hypothesis 1 . The divergence between the two sets of arguments are captured by the conflict between Hypotheses 2 and 3 - the former reflects that reciprocal dampening implies that the returns associated with mixed indicators are intermediate compared to those associated with uniform CSP; the latter reflects that rewarding uniformity implies that the returns associated with mixed indicators are worse than those associated with uniform CSP.

\subsection{Intra- and inter-dimensional CSP interactions}

Were the plurality of stakeholders to make overall judgements of a firm's degree of social (ir)responsibility - i.e. each makes a single judgement about a firm that spans all social and environmental issues - one might expect each stakeholder judgement to derive from a conceptual weighing of evidence from across all dimensions of CSP. This would permit positive 
and negative indicators in each CSP dimension to be viewed in light of positive and negative indicators in all other dimensions. However, an expectation for such pervasive interactions requires that stakeholders be comprehensively well-informed, is cognitively demanding (Barnett, 2012; Latin, 1993; Kahneman, 1973), and somewhat at odds with the tendencies for attention to be both greatly guided by salience (Fiske and Taylor, 1991) and biased towards connections between straightforwardly related information (Saimee, Shimp and Sharma, 2005). The processes through which stakeholders amass an information-set concerning CSR, judge CSR, and choose whether and how to condition their behaviour towards these firms accordingly, are non-trivial. As Barnett (2012) points out, the cognitive limitations of each individual stakeholder ensure that it is not certain that firm misconduct will be noticed, assessed and acted upon. Due to the enormous volume of available information facing stakeholders, and the imperative for individuals to efficiently allocate limited cognitive facilities to best fit numerous objectives, firm misconduct may be overlooked, or even if noticed, not punished.

Regarding noticing, Barnett argues that, "through both intentional and unconscious processes, people seek to use their limited attention to maximum benefit by selectively attending to those things that most fit with their goals and consequently ignoring those things that do not (Fiske and Taylor, 1991)". So, were individual stakeholders' interests aligned with some subset of CSP dimensions, one would not expect that their judgements to draw equally upon information relating to all CSP dimensions. Rather, one would expect stakeholders to pay particular attention to information relating to those issues - or that issue - in which they have a particular interest. This is not to say that individual stakeholders do not attend to a range of social and environmental issues when judging single companies. Indeed, there is some notable empirical support for an apparent propensity for strengths in corporate philanthropy to offset negatives in other dimensions of CSP - see, for example, studies by Godfrey et al. (2009) and Brammer et al. (2009). 
However, our purview is broader, as we investigate the financial effects of both positive and negative indicators across all CSP dimensions - where positives pertain not only to charitable giving - and how these financial impacts are differently realised in the presence of contradictory indicators. This breadth presents a large number of diverse potential CSP indicators, and a proportionately large set of potential cross-dimensional combinations of positives and negatives. To focus our study in a manner that acknowledges the cognitive demands on stakeholders, and their likely tactics in response, we assume that a CSP indicator is viewed in the context of those other indicators associated with the same firm that supply relevant context for the former because they pertain to the same CSP dimension, and so relate to consonant issues and jointly inform judgement of the priority placed by a firm on issues of that kind. For example, an indication that a firm has reduced its use of landfill will readily inform stakeholders' judgements of that firm's sensitivity to environmental issues. This connection brings an imperative to bring other indications of environmental performance to mind, such as, perhaps, the firm's record of habitat-threatening river pollution. Were the same firm to perform observably poorly on equal opportunities hiring - or some other non-environmental issue - it is not necessarily the case that stakeholders would attend to the comparison of this negative indicator with the positive indicator on the environment. Even were they to do so, it is also not straightforward that the stakeholder would, from this comparison, infer the firm is generally irresponsible, including a disregard for environmental issues, and take a dim view of their positive environmental indicators accordingly.

\section{DATA AND METHOD}

\subsection{CSP data}

We employ the Kinder, Lydenberg and Domini (KLD) STATS database as the source of CSP information. KLD is a social rating agency (now part of Morgan Stanley Capital International) 
which assesses firms' strengths and concerns with regard to several qualitative issue areas (community relations, diversity issues, employee programs, environment issues, product safety and quality, corporate governance and human rights) and controversial business issues (involvement in military contracting, nuclear power, firearms, alcohol, tobacco or gambling). The multiple merits of using the KLD database when conducting empirical research on the business case for CSR include, inter alia: a consistent application of objective criteria to assess CSP; an extensive coverage of large US firms since 1991; and a multidimensional approach to social performance (Sharfman, 1996; Waddock, 2003). Mattingly and Berman (2006) have observed that within the taxonomy of the KLD database, social strengths and concerns are distinct both conceptually and empirically, which for the purpose of this study is a desirable property of the data. Without a CSP measure that differentiates between positive and negative social and environmental impacts, we would not be able to focus upon uniform and mixed CSP as we intend. Furthermore, our use of KLD provides for firm samples of significant size, heterogeneity and time span, and by separately covering several dimensions of CSP, KLD permits us to match positive and negative indicators that pertain to consonant issues, and investigate whether the financial returns are differently realised in regards of different CSP dimensions.

We focus our study on the companies listed in the S\&P 500 Composite Index for the years between 1991 and 2008 inclusive. The unbalanced panel data sample used in our analyses comprises 6,986 firm-year observations, and covers 769 different firms over a period of 18 years. ${ }^{1}$ Following Hillman and Keim (2001), we focus upon the CSP dimensions that are omnipresent across the time period of interest: Community, Diversity, Employees, Environment, Product Safety and Quality (hereafter, Product). For each firm in each of these five CSP dimensions, we add the indicators of strength, and separately add the indicators of concern, in each year. We use these variables to determine whether, for each firm in each year and in regards of each dimension, there are uniformly positive indicators, uniformly negative 
indicators or a mix of positives and negatives. In addition, these totals are used to calculate normalised measures of positive and negative indicators. We do so by dividing each by the total number of potential indicators (positive and negative, respectively) listed for the relevant dimension in the KLD STATS database.

\subsection{Method}

The original sample is subdivided into several subsamples according to whether, in a particular CSP dimension and year, each firm exhibits only positive CSP indicators, only negative indicators or both. Overall, there are 15 different, partially overlapping subsamples (three for each of the five CSP dimensions). Our empirical approach is to model the antecedents of $\mathrm{CFP}^{2}$ by subsample and to compare in a manner that, for each CSP dimension, identifies any differential CFP across the three patterns of CSP indicators. Although we have an unbalanced panel of data, we employ an OLS regression that pools all observations together. In tests for redundant fixed effects applied to all relevant regressions, the null hypothesis of redundancy is not rejected. Therefore, it is most appropriate to retain the degrees of freedom that are saved by using pooled OLS rather than a fixed effects panel model.

It is well-established in the finance literature that certain types of stocks yield, on average, considerably higher returns than others. For example, stocks with the following characteristics typically yield higher returns than those having the opposite characteristics: the stocks of small companies; value stocks (i.e. those with low price-to-earnings ratios); stocks that have high exposures to general movements in the market as a whole (i.e. those with high capital asset pricing model betas); and stocks with momentum (i.e. that have experienced recent price increases). When estimating the financial effects of CSP, we control for these characteristics to ensure that differential CFP caused by these characteristics are not erroneously attributed to CSP. For example, were a relatively high proportion of firms with a particular type of CSP 
profile also small firms, we would expect to observe higher returns among this subsample purely because of firm size. By including size and the other characteristics in the model, we minimize the risk of misattributions of this kind.

Specifically, we include the following variables as controls in the time-series regressions: the excess market return, measured as the difference in returns between the S\&P 500 index and the yield on Treasury bills $\left(\mathrm{R}_{\mathrm{m}}-\mathrm{R}_{\mathrm{f}}\right)$, which are widely considered to be the marketable financial asset that bears the smallest amount of risk; the difference in returns between a portfolio of small stocks and a portfolio of large stocks, termed Small Minus Big portfolio returns (SMB); the difference in returns between a portfolio of value stocks with high book-value to market-value ratios and a portfolio of growth stocks with low book-value to market-value ratios, termed High Minus Low portfolio returns (HML); and a Momentum factor that measures the extent to which stocks that performed well in the past continued to do so. These factors have been shown to be amongst the most important determinants of stock returns in seminal studies of the literature of financial economics (Fama and French, 1992; Carhart, 1997). The data for all these stock performance controls are taken from Kenneth French's online data library.

For each subsample, the estimated alphas (i.e. the intercepts from the regressions - see Models (1) and (2) below) can be interpreted as the average return for the firms in that subsample after controlling for firm characteristics. Thus, we compare the financial effects of the different types of CSP profile by comparing the estimated alphas across the different subsamples. To overcome possible autocorrelation and heteroskedasticity issues in the error terms of the models, robust estimators are applied, and the first model specification employed separately for each subsample is:

$$
R_{i t}=\alpha_{i t-1}+\beta_{1}\left(R_{m t-1}-R_{f t-1}\right)+\beta_{2} S M B_{t-1}+\beta_{3} H M L_{t-1}+\beta_{4} M O M_{t-1}+\varepsilon_{i t}
$$


where $R_{i t}$ is the excess return of firm $i$ in year $t, R_{m t-1}$ is the lagged market return, $R_{f t-1}$ the risk free rate, $S M B$ is the small-minus-big factor, $H M L$ is the high-minus-low factor, $M O M$ the momentum factor as described above.

Tables I and II depict the mean values of the key financial variables and the median values for the respective firm-level variables across the various subsamples. In the tables, BETA is the average capital asset pricing model beta (a measure of market risk), $\ln (\mathrm{MV})$ is the natural logarithm of the market capitalisation of the firm, MTBV is the ratio of the market capitalisation of a firm to its book value and $\mathrm{N}$ is the number of observations in each subsample. It is evident that while there are indeed differences in the average values of the characteristics across subsamples, they are not of orders of magnitude. We also present, in the final column of both tables, the total number of observations per pool. While it is clear that the number of data points varies between the subsamples, well over 200 observations are available in all cases.

\section{INSERT TABLES I AND II ABOUT HERE}

For robustness, and in order to more formally compare the stock return performances of firms across subsamples associated with the same CSP dimension, we augment model (1) above using slope and intercept dummies. For example, in order to test whether the difference in alphas (i.e. the average returns) between the subsample of firms that have only positive indicators in Community and the subsample of firms that have only negative indicators in Community, we use the following model:

$$
\begin{aligned}
& R_{i t}=\alpha_{i t-1}+\alpha_{i t-1}^{\prime} S D_{i t-1}+\beta_{1}\left(R_{m t-1}-R_{f t-1}\right)+\beta_{2} S M B_{t-1}+\beta_{3} H M L_{t-1}+\beta_{4} M O M_{t-1} \\
& +\beta_{5}\left(R_{m t-1}-R_{f t-1}\right) S D_{t-1}+\beta_{6} S M B_{t-1} S D_{t-1}+\beta_{7} H M L_{t-1} S D_{t-1}+\beta_{8} M O M_{t-1} S D_{t-1}+\varepsilon_{i t}
\end{aligned}
$$

where the notation is as above but in addition: $S D$ is a dummy variable that takes a value of 1 if firm $i$ has only positive indicators in Community in year $t-1$, and takes a value of 0 if it has only 
negative indicators in Community. In those cases where $S D=0$, the excess return is equal to $\alpha$, and where $S D=1$, the excess return is equal to $\alpha+\alpha^{\prime}$. So, $\alpha^{\prime}$ is the difference between the excess returns of the two subsamples, which provides a basis to infer the financial returns associated with particular patterns of Community performance. This method is additionally applied to the other four dimensions of CSP, and also to test for differences between the excess returns associated with uniformly positive and mixed indicators, and separately for differences between the excess returns associated with uniformly negative and mixed indicators. Given the possibility that the KLD STATS ratings imperfectly reflect CSP (Chatterji, Levine, and Toffel, 2009), we employ an errors-in-variables regression approach (with a modest reliability ratio of 0.85 ) that ensures estimations are robust to such measurement error.

Consistent with preceding theoretical arguments, Models (1) and (2) above are estimated on subsamples constructed in a manner that discriminates between uniform and mixed indicators. However, in order to facilitate comparison with previous studies and address alternative explanations for our findings, it is useful to additionally construct subsamples based upon CSP measures that straightforwardly aggregate across the positive and negative indicators in each dimension. In order to perform such a task, we first calculate one aggregate measure for each of the Community, Diversity, Employee, Environment and Product dimensions, which, in each case is the deduction of normalised negative indicators from normalised positive indicators. We then sort the entire longitudinal sample according to the value of each of the aggregate measures, and separate these ordered distributions of firm-year observations in tertiles. The econometric method outlined above is applied to three subsamples - the first (best performance by this aggregate metric), second (intermediate performance by this aggregate metric) and third tertiles (worst performance by this aggregate metric) - for each CSP dimension. 


\section{RESULTS}

In Table III, we present, for each of the five CSP dimensions, estimated abnormal returns (alphas) associated with uniformly positive, uniformly negative and mixed indicators. These returns are found by regression estimations of Model (1). ${ }^{3}$ Entries in the table are parameter estimates and the standard errors in parentheses are calculated using autocorrelation and heteroskedasticity robust estimators. The dependent variable is the simple annual stock return and has been winsorized at the $1 \%$ level; $\alpha$ is a measure of abnormal returns after controlling for the financial variables. All but one of the longitudinal subsamples of firm-year observations - the exception is associated with mixed indicators in Community - are found to have statistically significant abnormal returns. Within-dimension comparisons of returns across the three subsamples identify a common pattern found for four of the five dimensions. For Community, Diversity, Employee and Product: the highest estimated abnormal returns are associated with uniformly positive indicators; the second highest are associated with uniformly negative indicators; and the lowest are associated with mixed indicators. For Environment, the pattern is different, with: the highest returns associated with uniformly negative indicators; the lowest returns associated with uniformly positive indicators; and mixed indicators associated with intermediate returns. While, for Environment, the abnormal returns are relatively similar across the three subsamples (a difference from highest to lowest of $2.36 \%$ ), it is worth noting that the differences found for the other four dimensions are much larger. For Employee, the difference in returns between uniformly positive and mixed indicators is (at $5.43 \%$ ) more than double the largest disparity found for Environment. For Diversity and Product, the equivalent differences are larger still (8.65\% and $13.44 \%$, respectively), but the largest difference in returns between uniformly positive and mixed indicators is found for Community - where the abnormal returns associated with the former are $16.46 \%$ larger than those associated with the latter (i.e. $19.75 \%$ compared to $3.29 \%$ ). 
Table IV focuses upon these disparities, and presents, for each CSP dimension, pair-wise comparisons of abnormal returns (net alphas) across the three subsamples, which (as in Table III) are drawn according to whether uniformly positive, uniformly negative or mixed indicators are exhibited at the firm-level. These comparisons derive from pooled regression estimations using Model (2), which estimates the disparities in returns more efficiently than Model (1), and provides evidence of the degree to which any such disparities are statistically significant. Autocorrelation and heteroskedasticity robust standard errors are employed and we follow an errors-in-variables estimation approach with a reliability ratio of 0.85 to account for possible measurement errors in corporate social performance. For each CSP dimension, we compute pair-wise comparisons of the different combinations of subsamples. For example, the third row of the table reports a t-test that compares the subsample with uniformly positive Community indicators and the subsample with uniformly negative Community indicators. Again, for four of the five dimensions - Community, Diversity, Employee and Product - the same pattern is found. In support of Hypothesis 1, our findings for these dimensions associate uniformly positive CSP indicators with better financial returns than those associated with uniformly negative indicators. Contrary to Hypothesis 2 but in support of Hypothesis 3 , they also indicate that the financial returns associated with uniform CSP indicators - whether positive or negative - outperform those associated with a mix of positive and negative indicators CSP. The reported effects on CFP are especially high for Community, in which firms with uniformly positive and uniformly negative indicators outperform those with mixed indicators by $19.39 \%$ and $11.25 \%$, respectively. Given the magnitude of these effects, it is unsurprising that the CFP differences described in Hypotheses 1 and 3 are found to be statistically significant for Community ( $p=0.000$ and $\mathrm{p}=0.004$, respectively).

Our findings for Product offer similarly statistically significant support for Hypotheses 1 and $3(\mathrm{p}=0.003$ and $\mathrm{p}=0.070$, respectively). The support for Hypothesis 1 from the Employee 
dimension is also statistically significant $(\mathrm{p}=0.064)$. For Diversity, the estimated returns are consistent with Hypothesis 1 - that uniformly positive indicators are associated with better returns than those associated with uniformly negative returns - but the disparity between the subsamples is not statistically significant $(\mathrm{p}=0.656)$. While the patterns of estimated returns associated with Diversity and Employee are consistent with Hypothesis 3 (and the opposite of that implied by Hypothesis 2), the reported disparities between the returns associated with uniformly negative and mixed indicators are not statistically significant $(p=0.149$ and $p=0.723$, respectively). The findings for the other dimension - Environment - do not support any of the hypotheses, as the abnormal returns associated with uniformly positive indicators are lower than those associated with both uniformly negative and mixed indicators. One should note that the differences in returns reported for Environment are relatively small and not statistically significant.

\section{INSERT TABLES III AND IV ABOUT HERE}

The evidence presented in Tables III and IV provides support for Hypotheses 1 and 3, and no support for Hypothesis 2. Thus, consistent with the arguments forwarded in the development of our hypotheses, the support for rewarding uniformity in stakeholder judgements of CSR is starkly stronger than that for reciprocal dampening. However, before discussing the implications of our findings in section 5, we will report the results of further analyses, which address alternative potential explanations of our results.

\subsection{Further analyses}

We will consider two potential alternative explanations in turn. Each contradicts the view of stakeholder judgements of CSR that we have previously forwarded. The first alternative 
explanation is the prospect that our results derive from a tendency for stakeholder judgements to be critically determined by the relative prevalence of positive and negative indicators, rather than a particular sensitivity to uniform and mixed indicators. The results may be interpreted in this way if uniformly positive, uniformly negative and mixed CSP profiles tend to exhibit high, low and moderate levels of aggregate CSP, respectively. To illustrate this point: Rewarding uniformity implies a significant distinction between a CSP profile of three positive indicators with one negative indicator, and one of two positive indicators and no negative indicators - the former is mixed CSP, while the latter is uniform CSP. However, the potential alternative explanation is consistent with stakeholders taking a similar view of both cases, as the net number of positives over negatives is two in both cases. To investigate whether the financial returns we identify are better explained with reference to tendencies for firms to exhibit high, low and intermediate relative prevalence of positive over negative indicators, we analyse subsamples for each CSP dimension drawn according to whether each firm's aggregate CSP is placed in the top, middle or bottom third of the sample in each year. As explained in a previous section: aggregate CSP is calculated as a net score that deducts the prevalence of negative indicators from the prevalence of positive indicators.

Table V presents the results from an equivalent estimation of Model (2) as was used to provide the results presented in Table IV, but for the subsamples differently drawn to reflect differently ranked aggregate CSP - top, middle and bottom tertiles - in each dimension. The results presented in Table $\mathrm{V}$ are starkly different to those presented in Table IV. It is first worth noting that Table $\mathrm{V}$ presents smaller disparities in returns than are presented in Table IV. Also, for four of the five dimensions, there is no statistically significant disparity in estimated returns across subsamples. Moreover, the pattern of returns across the tertiles varies greatly across dimensions, and for none of the five dimensions do the results exhibit a pattern in returns that reflects either rewarding uniformity or reciprocal dampening in stakeholder judgements. Consistent with 
our previous arguments, our evidence suggests that the distinction between uniform and mixed indicators is more influential than aggregate CSP (which reflects the relative prevalence of positive and negative indicators) in determining the financial returns associated with CSP. It is worth noting that this finding echoes the prior findings of Strike, Gao and Bansal (2006) and the arguments of Mattingly and Berman (2006) that, because positives and negatives are conceptually, as well as empirically, distinct, they should not be aggregated. Doing so, they argue, is likely to hinder investigation of the relationship between CSP and CFP and lead to less informative or even misleading conclusions.

\section{INSERT TABLE V ABOUT HERE}

The second alternative explanation we consider arises from the contention that the uniform and mixed CSP indicators may be proxy measures of broader tendencies in corporate strategy (Brammer and Millington, 2008). The idea is that it is these more pervasive strategic positions of firms that generate the disparities in returns, rather than CSP and the associated stakeholder judgements of CSR. In this connection, one might contend that: firms with uniformly positive CSP tend be those that follow a product differentiation strategy; firms with uniformly negative indicators tend to be those that follow a cost leadership strategy; and firms with mixed CSP indicators tend to be those that follow a strategy that mixes elements of the both differentiation and cost leadership. We test this rationale using two variables that reflect such strategic positions: asset turnover and net profit margin (Little, Little and Coffee, 2009). The expectation is that firms following a differentiation strategy are characterized by high profit margins and low asset turnover - as they target relatively low volumes of total sales and have correspondingly low utilization rates of their assets - while firms following a cost leadership 
strategy are characterized by low profit margins and high asset turnover - as they target relatively high volumes of total sales and have correspondingly high utilization rates of their assets.

Using these variables, we conduct two sets of analyses. First, we estimate subsample mean values for both variables and, for each CSP dimension, conduct pair-wise equality tests across subsamples. When comparing across subsamples, for neither variable do we find disparities between the mean values that are consistent with the above contention. Furthermore, only four out of a total of thirty such comparisons reveal a statistically significant difference between the mean values of these variables. Second, for each subsample, we regress the two strategy variables on firm size and industry dummies and calculate their intercepts, which provides average values of asset turnover and net profit margin which control for size and industry. Echoing the results of the first analysis, no consistent pattern arises to support the contention that uniform and mixed CSP profiles proxy for broader firm strategy in the manner described above - detailed results of these analyses are available from the authors upon request.

Furthermore, to investigate the robustness of our results regarding uniform and mixed CSP to the use of other, accounting-based measures of CFP, we repeat the type of approach described in Model (2) using the Earnings per Share to Price ratio and Return on Equity as the dependent variables. The change in dependent variable necessitates a change in control variables, as the four-factor model we have employed in our main analysis is suitable for only models that explain stock returns. In this additional analysis, we instead control for firm size, market to book value (used to separate firms with different growth prospects), total debt to common equity (captures firm leverage) and a series of industry dummy variables. Although this yields results that do not so strongly support rewarding uniformity as does our analyses of stock returns, 22 out of the 30 pair-wise comparisons across subsamples are consistent with rewarding uniformity and all eight of the 30 that are statistically significant are - consistent with rewarding uniformity - also positive. (Detailed results from these additional analyses are available from the authors.) 
Lastly, in order to investigate whether our findings are subject to omitted variable bias, we conduct two additional analyses that make use of additional control variables that have been used in prior empirical CSP-CFP research. The addition to Model (1) of dividend yield (corporate policy), total-debt-to-common-equity ratio (financial leverage), research-anddevelopment-expenditure-to-total-sales ratio ( $R \& D$ intensity) and a series of industrial dummy variables constructed using the Industry Classification Benchmark (ICB) leaves the results previously reported on our variables of interest substantively unchanged. Given that the addition of these variables brings only slight changes in our reported estimates, which preserve all key aspects and implications of our findings, strongly suggests no meaningful presence of omitted variable bias.

\section{CONCLUDING REMARKS}

This study investigates the relationship between CSP and CFP, and specifically the degree to which this relationship is critically determined by the differential financial impacts of uniformly positive, uniformly negative and mixed (positive and negative) indicators by the same firm. In this connection, we employ notions of cue diagnosticity from social judgement theory (Mishina et al., 2012) to forward two competing views of how uniform and mixed CSP may be differently judged by stakeholders - termed reciprocal dampening and rewarding uniformly. Both imply that uniformly positive CSP is more favourably viewed than uniformly negative CSP, but they differ in the expected returns from mixed CSP: the former implies that mixed CSP is viewed as indicative of an intermediate degree of CSR (between those inferred from uniform CSP); the latter implies that mixed CSP is the most dimly viewed (less favourable than those inferred from uniform CSP) due to the superior diagnosticity of negative indicators and/or negative inferences associated with perceived ingratiation (Godfrey, 2005). We assume that these stakeholder judgements translate into stakeholders' willingness to enter into, and sustain, interactions with 
firms that contribute to CFP, and thereby hypothesise that: the financial returns from uniformly positive CSP are better than those from uniformly negative CSP (Hypothesis 1); that there are intermediate financial returns from mixed CSP (Hypothesis 2); that the financial returns from mixed CSP are worse than those from uniform CSP, whether positive or negative (Hypothesis 3). Our findings for large US firms (and using KLD social ratings to measure CSP) provide significant support for Hypotheses 1 and 3, which suggests that, in stakeholder judgements, there is a far stronger tendency for rewarding uniformity than reciprocal dampening.

As mentioned above, our study applies some key insights from social judgement theory in regards of reputational judgements of corporate character. Specifically, we test hypotheses derived from arguments that, within such judgements, negative cues are viewed as more strongly diagnostic than positive cues, and through patterns in the CSP-CFP relationship provide novel evidence in support. In addition, our study offers useful insights for the development of social judgement theory as we present an account of reputational judgements of corporate character that synthesises the above-mentioned insights on cue diagnosticity and notable arguments regarding the imputation of corporate motives (Godfrey, 2005). Indeed, it is the characterisation of reputational judgements that derives from this synthesis - rewarding uniformity - that our findings support. This suggests that, given a mix of positive and negative cues, such CSR judgements are relatively highly responsive to negative cues and subject to inferences that positive cues are motivated by a desire to deceive stakeholders. So, our study supports the notion that reputational judgements of mixed CSP tend to not only place greater weight on bad news, but also view good news in a negative light.

It is, of course, important to note that the evidence in support of Hypotheses 1 and 3 extends to only four of the five CSP dimensions investigated - Community, Diversity, Employee and Product - for which significant abnormal returns are found that conform to rewarding uniformity. For Environment, the pattern of financial returns conforms to neither rewarding 
uniformity nor reciprocal dampening, and instead the abnormal returns associated are relatively similar across all three types of CSP profile - uniformly positive, uniformly negative and mixed indicators. While our results do not permit us to infer why the results for Environment differ starkly from those for all other dimensions studied - and this puzzle presents an interesting topic for future research - we suggest a potential reason why environmental issues emerge as different in this regard: environmental issues, while no less pressing or impactful, tend to be somewhat less pervasively relevant across business sectors than those relating to the other four dimensions.

As firms are very commonly located in communities, employ workers, provide products and are expected to offer equal opportunities, community, diversity, employee and product issues are relatively equally relevant across a broad range of sectors. However, many environmental issues are very differently salient in different sectors. For example, a variety of pollution and hazardous waste issues that typically confront companies in the chemicals, resources and some other sectors, do not typically arise in connection with the operations of banks, retailers and numerous other sectors. As a result, one expects great variation across industries in both environmental CSP - as the threat of some negative indicators is considerably greater in a subset of industries - and the breadth of environmental issues against which firms are judged by stakeholders - as some issues arise in only some industries (Brammer and Pavelin, 2004, 2006). Such cross-industry variation may have hindered our investigation of what, in general, across all industry contexts, are the financial effects of environmental CSP.

It is also worth noting that our results echo some key prior findings on strategic consistency, which have identified financial penalties associated with inconsistency. From mixed CSP, one might infer a within-firm inconsistency in how different business units or business functions address consonant CSR issues; whereas, from uniform CSP one might infer more consistent cross-firm adherence to a corporate positioning on such issues. If so, our study offers additional support for the notion that strategic consistency is financially beneficial. However, the 
rejection of reciprocal dampening is perhaps somewhat surprising. It is intuitively appealing to expect that mixed CSP would be judged moderately positively and be associated with intermediate financial returns. However, our results suggest that the diagnostic value of negative CSP indicators is sufficiently strong to ensure that any coincident positive indicators are associated with harm to CFP. This is consistent with positive indicators being dimly viewed by stakeholders if alongside indicators of negative CSP in the same dimension, i.e. positive CSP negatively influences perceived CSR because the resulting mix of positives and negatives leads stakeholders to infer ingratiation on the part of the firm.

Our key findings somewhat echo a few previous studies that have indicated a U-shaped relationship between CSP and CFP, i.e. that both the lowest and highest levels of CSP are, all other things equal, associated with higher levels of CFP than is associated with intermediate levels of CSP. For example, Brammer and Millington's (2008) study of UK firms over the period 1990-1999 found a U-shaped relationship between corporate philanthropy and CFP, which they explain with reference to two alternative routes to competitive advantage - low-cost and differentiation - and to the likelihood that firms will perform relatively poorly if they follow a strategy that falls some way between the two (Porter, 1980). Their analysis suggests that firms donating relatively small or large amounts (compared to the amounts predicted by firm size, industry and other control variables) enjoy better CFP than those whose donations lay between the two extremes. More specifically, from their analyses of philanthropy, they concluded, "that firms with both unusually high and low social performance have higher financial performance than other firms with unusually poor social performers doing best in the short run, and unusually good social performers doing best over longer time horizons" (p.1341).

Somewhat similarly, a study of SRI fund performance by Barnett and Salomon (2006) found a U-shaped relationship among the returns, such that the SRI performance is found to be better when the strongest or weakest screening criteria are employed, rather than screening that 
lies somewhere between the two. In a more recent study, which is the most closely related to ours, the same authors report a U-shaped firm-level relationship between CSP and CFP - for a large US sample of firms, they report that the worst performers on a single, aggregate CSP score (derived from KLD social ratings) have higher CFP than firms with moderate CSP, but the best CFP is found for the best social performers (Barnett and Salomon, 2012). That their study reports a U-shaped CSP-CFP link is seemingly inconsistent with the results we report in Table V, which find no tendency for better financial returns from the best and worst levels of aggregate, overall CSP. However, in this connection, it is worth noting that Barnett and Salomon (2012) use accounting, profit-based measures of CFP, rather than stock market-based CFP as here. Thus, it seems that accounting-based, flow measures of CFP and measures derived from share values which determine the total value of corporations - are differently determined by CSP.

While our findings that uniform CSP - whether positive or negative - financially outperforms mixed CSP are redolent of these prior results, they substantively differ. Our focus upon the distinction between uniform and mixed CSP is novel, as the above mentioned studies instead focus upon the presence and absence of creditable charitable giving, portfolio screening criteria, and notions of aggregate, net CSP that imply some deduction of negatives from positives, respectively. None of those approaches reflects the potential for stakeholder judgements of CSR to be critically and decisively determined by the powerful diagnostic value of negative CSP indicators, and the tendency that this implies for positive indicators to be differently viewed if alongside negative indicators. Furthermore, we not only extend the purview beyond a relatively narrow focus upon corporate philanthropy, but also unpick CSP into constituent dimensions that gather together information on related issues. By doing so, we present evidence of how the financial returns on uniform and mixed CSP indicators are differently realised in regards of the different dimensions studied. 
There are, of course, limitations to the scope of our study. Most obviously, its focus upon relatively large, publicly-traded US companies ensures that its findings do not straightforwardly generalise to smaller, private or state-owned, and/or non-US companies. The investigation of the same research questions among such (perhaps materially) different classes of firms and business environments is an interesting avenue for future research. Another limitation is the indirectness of our testing of hypotheses that derive from the nature of stakeholder judgements of CSR. Rather than undertake a direct study of stakeholder judgements - whereby one would elicit such perceptions from stakeholders - we study the relationship between CSP and CFP in the expectation that these judgments are reflected in impacts on CFP due to their influence on stakeholder behaviour. The study of stakeholder judgements offers a pleasingly direct avenue for future research, which may provide useful confirmatory evidence of our supporting arguments. Of course, in undertaking any such work, researchers must navigate the difficulties that arise when seeking to reliably elicit attitudes towards, and judgements of, CSR e.g. social desirability bias (such that responses may be unduly biased by respondents' desires to meet social expectations perceived in the research setting; Fisher, 1993) and artificiality in the research setting (such as the use of hypothetical firms and events, and the lack of the types and magnitudes of risks and rewards that are commonly associated with real-world stakeholder behaviour; Keppel and Wickens, 2004).

It is also worth noting that our study encompasses CSP in relation to numerous types of issues, and that a narrower focus would permit a more detailed study of a particular component of CSP or single social or environmental issue. Indeed, in the design of empirical work, one commonly faces trade-offs between generality of scope and richness of detail. In our study, we have chosen to resolve such a trade-off by considering a range of CSP components, while preserving the distinctions between a few, relatively disparate components. Finer-grained analyses of particular, single issues are potentially informative avenues for future research, which 
may shed light on richness within the broader tendencies we identify - including differences between apparently similar issues in regards of the relationships observed between CSP and CFP. Another route to finer-grained detail may be provided by the prospect of heterogeneity within the three categories of firm-level CSP - uniformly positive, uniformly negative and mixed CSP. While our findings suggest that this trichotomy holds significant explanatory power within the relationship between CSP and CFP, they do not rule out the possibility of notable variation among firms that exhibit the same category of CSP profile. For example, two firms that each exhibit mixed CSP may - due to influential differences in the composition of CSP across positive and negative indicators - be found to materially differ in the associated impacts on CFP. Though such an endeavour would present theoretical challenges, the search for such within-group heterogeneity may be a fruitful avenue for future research.

Our findings provide lessons for practice for both investors and managers. For investors, our findings suggest that stock-selection criteria that focus upon the presence of either positive indicators or negative indicators - by, for example, favouring firms that exhibit positive indicators or screening out firms that exhibit negative indicators - will not systematically attract the identified abnormal financial returns. To benefit from these financial returns, an investor must look across firms' CSP profiles in particular dimensions and inspect the manner in which they are comprised of positive and negative indicators. It is only by utilising selection criteria that take into account information about both positives and negatives that an investor can expect to reap the considerable abnormal returns we identify in our study. Moreover, while the biggest financial rewards are associated with uniformly positive indicators, our results also imply that investors favouring uniform CSP profiles would, whether the selected firms exhibit only positive or only negative indicators, outperform portfolios of firms that exhibit mixed CSP in particular dimensions. 
In order to reap the financial rewards highlighted in this study, managers should seek to avoid offering to stakeholders a mix of positive and negative indicators within a narrow spectrum of consonant social issues. Our study provides a financially-grounded rationale for firms to focus upon building CSP strengths in those dimensions in which the firm is not simultaneously exhibiting notable weaknesses. Numerous high profile cases have demonstrated that the ethical and reputational impetus to address an area of extant weakness can be compelling, as perceptions of a firm can be greatly damaged by large-scale, adverse media coverage that highlights social harm done. We find a tendency for the largest financial returns to be associated with CSP profiles that avoid such negative indicators. Furthermore, if a negative indicator arises for a firm, investments in CSR initiatives that, in response, eradicate the negative will attract financial rewards; however, responses that generate positives in the same CSP dimension but permit the negative indicator to remain will incur a financial penalty.

This may be seen to imply a worrying - from a social welfare viewpoint - undermining of the incentives for corporate managers to invest in CSP. Indeed, it implies a tendency for firms that make incremental steps to improve their CSP from the bottom end of the spectrum to suffer financial penalties during their potentially costly and lengthy period of transition towards creditable CSP. For all the while that such a firm exhibits negative indicators, their financial returns on CSP are expectably worsened by the diagnostic power of such bad news. Despite any partial improvements in actions and impacts, the firm risks damaging character judgements that could be expressed as: a responsible firm would not behave that way; or no firm that really cared would do such harm. However, while the findings of this paper appear to highlight this problem, it also identifies the most effective way for a firm that initially performs poorly on CSP to navigate their way to reputational chits in regards of CSR, such that onerous reputational and financial penalties are minimised along the way. 
Specifically, in order to make such a transition as financially painless as possible, a firm should target their investments to avoid the prospect that the firm's initiatives are perceived to address issues on which the firm continues to be negatively viewed. To benefit from the financial returns we identify, managers should invest in CSP in a manner that addresses a firm's position to prioritise the removal of weaknesses. While positive news about a firm's CSP is expectably rewarded if it eradicates countervailing evidence, damage to returns is expected if the firm's efforts to address a social and/or environmental issue permit the persistence of wrongdoing and/or harm. Therefore, a firm that desires to avoid financial penalties while making marked improvements in its CSP should channel efforts and resources towards those issues in which it seeks, in due course, to demonstrate strength but on which it is initially weak. By addressing these issues and - crucially - making meaningful, effective responses to put an end to the firm's negatively-viewed actions and impacts, a firm would be expected to most fully harnesses market rewards during its transition to a creditable CSP record. That the greatest financial returns are associated with uniformly positive CSP provides a stark imperative for firms to first address any aspects of its conduct that are perceived to imply crass irresponsibility or significant harm. It is from such a foundation that a firm can build its financial performance through its contribution to society, by avoiding, in regards of CSP, the presentation of a mixed picture. 


\section{NOTES}

1 Given the purpose of our study, it is necessary to include data for only firm-years with at least one positive and/or negative indicator. Nevertheless, as the summary statistics demonstrate, we have a sizeable and very diverse sample in regards of key financial characteristics. So, we do not believe that the results are biased due to the exclusion of these observations.

2 As our preceding arguments relate to stakeholders' judgements of firms, it would be a most direct test of this theory to investigate the antecedents of these perceptions, rather than CFP. However, a focus upon the CSP-CFP link is, we argue, appropriate. First, the stakeholder judgements of CSR play a pivotal role in the account of the business case for CSR provided by Instrumental Stakeholder Theory. Therefore, it is well-grounded in theory that the nature of stakeholder judgements of CSR will significantly determine the nature of the CSP-CFP link. Second, our focus upon financial returns ties in with, and makes a novel contribution to, an established line of enquiry that is well-placed to offer informative lessons for managerial practice. Third, reputational indices (such as those published by Fortune and Management Today) reflect judgements of CSR to only a minor extent and are instead largely driven by perceptions of firms' financial performance.

3 Although the coefficients associated with the financial control variables are small in size and some are statistically insignificant, this output is broadly consistent, in terms of the sizes, signs and significance of the coefficients, with the findings of Galema, Plantinga and Scholtens (2008) who implement a similar methodology. Of course, these slope parameters are not the focus of our study - we merely include these variables to ensure that we obtain alpha estimates that are purged of the influences of these factors. 


\section{REFERENCES}

Arya, B and Zhang, G. (2009). 'Institutional reforms and investor reactions to CSR announcements: Evidence from an emerging economy'. Journal of Management Studies, 46, 1089-112.

Baier, C., Hartmann, E. and Moser, R. (2008). 'Strategic alignment and purchasing efficacy: An exploratory analysis of their impact on financial performance'. Journal of Supply Chain Management, 44, 36-52.

Barnett, M. (2013). 'Why stakeholders ignore firm misconduct: A cognitive view'. Journal of Management, forthcoming.

Barnett, M. and Salomon, R. (2006). 'Beyond dichotomy: The curvilinear relationship between social responsibility and financial performance'. Strategic Management Journal, 27, 1101-22.

Barnett, M. and Salomon, R. (2013). 'Does it pay to be really good? Addressing the shape of the relationship between social and financial performance'. Strategic Management Journal, forthcoming.

Brammer, S.J., Brooks, C. and Pavelin, S. (2006). 'Corporate social performance and stock returns: UK evidence from disaggregate measures'. Financial Management, 35, 97-116.

Brammer, S.J., Brooks, C. and Pavelin, S. (2009). 'The stock performance of America's 100 Best Corporate Citizens'. Quarterly Review of Economics and Finance, 49, 1065-80.

Brammer, S.J. and Millington, A.I. (2008). 'Does it pay to be different? An analysis of the relationship between corporate social and financial performance'. Strategic Management Journal, 29, 1325-43.

Brammer, S.J., Millington, A.I. and Rayton, B.A. (2007). 'The contribution of corporate social responsibility to organizational commitment'. International Journal of Human Resource Management, 18, 1701-19.

Brammer, S.J. and Pavelin, S. (2004). 'Building a good reputation'. European Management Journal, 22, 
$704-13$.

Brammer, S.J. and Pavelin, S. (2006). 'Corporate reputation and social performance: The importance of fit'. Journal of Management Studies, 43, 435-55.

Brammer, S.J., Pavelin, S. and Porter, L.A. (2009). 'Corporate charitable giving, multinational companies and countries of concern'. Journal of Management Studies, 46, 575-98.

Bromberg M. and Fine, G.A. (2002). 'Resurrecting the red: Pete Seeger and the purification of difficult reputations'. Social Forces, 80, 1135-55.

Carhart, M.M. (1997). 'On persistence in mutual fund performance'. Journal of Finance, 52, 57-82.

Chatterji, A.K., Levine, D.I. and Toffel, M.W. (2009). 'How well do social ratings actually measure corporate social responsibility?' Journal of Economics and Management Strategy, 18, 125-69.

Clarkson, M.B.E. (1995). 'A stakeholder framework for analyzing and evaluating corporate social performance'. Academy of Management Review, 20, 92-117.

Cox, P., Brammer, S.J. and Millington, A.I. (2004). 'An empirical examination of institutional investor preferences for corporate social performance'. Journal of Business Ethics, 52, 27-43.

Fama, E. and French, K. (1992). 'The cross-section of expected stock returns'. Journal of Finance, $47,427-65$.

Fisher, R. (1993). 'Social desirability bias and the validity of indirect questioning'. Journal of Consumer Research, 20, 303-15.

Fiske, S. and Taylor, S. (1991). Social Cognition (2nd edition). New York: Random House.

Freeman, R.E. (1984). Strategic Management: A Stakeholder Approach. Boston: Pitman.

Galema, R., Plantinga, A. and Scholtens, B. (2008). 'The stocks at stake: Return and risk in socially responsible investment'. Journal of Banking \& Finance, 32, 2646-54.

Godfrey, P.C. (2005). 'The relationship between corporate philanthropy and shareholder wealth: A risk management perspective'. Academy of Management Review, 30, 777-98. 
Godfrey, P.C., Hatch, N.W. and Hansen, J.M. (2010). 'Toward a general theory of CSRs'. Business \& Society, 49, 316-44.

Godfrey, P.C., Merrill, C.B. and Hansen, J.M. (2009). 'The relationship between corporate social responsibility and shareholder value: An empirical test of the risk management hypothesis'. Strategic Management Journal, 30, 425-45.

Griffin, J.J. and Mahon, J.F. (1997). 'The corporate social performance and corporate financial performance debate'. Business \& Society, 36, 5-31.

Harrison, J.S., Hall, E.H. and Nargundkar, R. (1993). 'Resource allocation as an outcropping of strategic consistency: Performance implications'. Academy of Management Journal, 36, 102651.

Hillman, A.J. and Keim, G.D. (2001). 'Shareholder value, stakeholder management, and social issues: What's the bottom line?' Strategic Management Journal, 22, 125-39.

Hollander, E.P. (1958). 'Conformity, status, and idiosyncrasy credit'. Psychological Review, 65, $117-$ 27.

Jones, E.E. and Pittman, T.S. (1982). 'Toward a general theory of strategic self-presentation'. Psychological Perspectives on the Self, 1, 231-62.

Jones, T.M. (1995). 'Instrumental stakeholder theory: A synthesis of ethics and economics'. Academy of Management Review, 20, 404-37.

Joshi, M.P., Kathuria, R. and Porth, S.J. (2003). 'Alignment of strategic priorities and performance: An integration of operations and strategic management perspectives'. Journal of Operations Management, 21, 353-69.

Kahneman, D. (1973). Attention and Effort. New Jersey: Prentice-Hall.

Kathuria, R., Joshi, M.P. and Porth, S.J. (2007). 'Organizational alignment and performance: Past, present and future'. Management Decision, 45, 503-17.

Keppel, G. and Wickens, T.D. (2004). Design and Analysis: A Researcher's Handbook. New Jersey: 
Prentice Hall.

Kotchen, M.J. and Moon, J.J. (2007). 'Corporate social responsibility for irresponsibility'. NBER Working Paper No. 17254.

Lamberg, J.-A., Tikkanen, H., Nokelainen, T. and Suur-Inkeroinen, H. (2009). 'Competitive dynamics, strategic consistency, and organizational survival'. Strategic Management Journal, 30, 45-60.

Latin, H. (1993). 'Good warnings, bad products, and cognitive limitations'. UCLA Law Review, 41, 1193-295.

Little, P.L., Little, B.L. and Coffee, D. (2009). 'The Du Pont Model: Evaluating alternative strategies in the retail industry'. Academy of Strategic Management Journal, 8, 71-80.

Love, E.G. and Kraatz, M. (2009). 'Character, conformity, or the bottom line? How and why downsizing affected corporate reputation'. Academy of Management Journal, 52, 314-35.

Margolis, J.D. and Walsh, J.P. (2003). 'Misery loves companies: Rethinking social initiatives by business'. Administrative Science Quarterly, 48, 268-305.

Mattingly, J.E. and Berman, S.L. (2006). 'Measurement of corporate social action'. Business \& Society, $45,20-46$.

McWilliams, A. and Siegel, D.S. (2000). 'Corporate social responsibility and financial performance: correlation or misspecification?' Strategic Management Journal, 21, 603-9.

Mishina, Y., Block, E.S. and Mannor, M.J. (2012). 'The path dependence of organizational reputation: How social judgment influences assessments of capability and character'. Strategic Management Journal, 33, 459-77.

Mitchell, R.K., Agle, B.R. and Wood, D.J. (1997). 'Toward a theory of stakeholder identification and salience: Defining the principle of who and what really counts'. Academy of Management Review, 22, 853-86.

Nath, D. and Sudharshan, D. (1994). 'Measuring strategy coherence through patterns of strategic 
choices'. Strategic Management Journal, 15, 43-61.

Oikonomou, I., Brooks, C. and Pavelin, S. (2012). 'The impact of corporate social performance on financial risk and utility: A longitudinal analysis'. Financial Management, 41, 483-515.

Pomering, A. and Dolnicar, S. (2009). 'Assessing the prerequisite of successful CSR implementation: Are consumers aware of CSR initiatives?' Journal of Business Ethics, 85, 285-301.

Porter, M.E. (1980). Competitive Strategy: Techniques for Analyzing Industries and Competitors. New York: Free Pass.

Porter, M.E. and Kramer, M.R. (2002). 'The competitive advantage of corporate philanthropy'. Harvard Business Review, December, 57-68.

Rao, P. and Holt, D. (2005). 'Do green supply chains lead to competitiveness and economic performance?' International Journal of Operations and Production Management, 25, 898-916.

Samiee, S., Shimp, T.A. and Sharma, S. (2005). 'Brand origin recognition accuracy: Its antecedents and consumers' cognitive limitations'. Journal of International Business Studies, 36, 379-97.

Sen, S. and Bhattacharya, C.B. (2001). 'Does doing good always lead to doing better? Consumer reactions to corporate social responsibility'. Journal of Marketing Research, 38, 225-43.

Sharfman, M. (1996). 'The construct validity of the Kinder, Lydenberg \& Domini social performance ratings data'. Journal of Business Ethics, 15, 287-96.

Strike, V.M., Gao, J. and Bansal, P. (2006). 'Being good while being bad: Social responsibility and the international diversification of US firms'. Journal of International Business Studies, 37, 850-62.

Tang, Z. Hull, C.E. and Rothenberg, S. (2012). 'How corporate social responsibility engagement strategy moderates the CSR-financial performance relationship'. Journal of Management Studies, 49, 1274-303. 
Vanhamme, J. and Grobben, B. (2009). 'Too good to be true! The effectiveness of CSR history in countering negative publicity'. Journal of Business Ethics, 85, 273-83.

Waddock, S. (2003). 'Myths and realities of social investing'. Organization \& Environment, 16, 36980.

Waddock, S.A. and Graves, S.B. (1997). 'The corporate social performance-financial performance link'. Strategic Management Journal, 18, 303-19.

Wood, D.J. (1991). 'Corporate social performance revisited'. Academy of Management Review, 16, 691-718.

Wood, D.J. and Jones, R.E. (1995). 'Stakeholder mismatching: A theoretical problem in empirical research on corporate social performance'. International Journal of Organizational Analysis, 3, $229-67$.

Yoon, Y., Gürhan-Canli, Z. and Schwarz, N. (2006). 'The effect of corporate social responsibility activities on companies with bad reputations'. Journal of Consumer Psychology, 16, 377-90. 
Table I

Median values of three firm characteristics

\begin{tabular}{|l|l|r|r|r|r|}
\hline Dimension & Subsample & BETA & $\ln (\mathbf{M V})$ & MTBV & \multicolumn{1}{c|}{ N } \\
\hline \multirow{4}{*}{ Community } & Uniformly positive & 0.943 & 9.028 & 2.452 & 1446 \\
& Mixed & 1.033 & 10.260 & 2.314 & 253 \\
& Uniformly negative & 0.952 & 9.225 & 2.152 & 701 \\
\hline \multirow{5}{*}{ Diversity } & Uniformly positive & 0.961 & 9.169 & 2.883 & 2797 \\
& Mixed & 0.958 & 10.128 & 2.609 & 519 \\
& Uniformly negative & 1.012 & 8.865 & 2.314 & 236 \\
\hline \multirow{5}{*}{ Employee } & Uniformly positive & 0.971 & 9.093 & 2.992 & 2076 \\
& Mixed & 1.067 & 9.472 & 2.495 & 671 \\
& Uniformly negative & 0.944 & 8.929 & 2.249 & 1036 \\
\hline \multirow{3}{*}{ Product } & Uniformly positive & 0.858 & 8.887 & 2.639 & 671 \\
& Mixed & 0.902 & 9.113 & 2.397 & 837 \\
& Uniformly negative & 0.829 & 8.909 & 2.177 & 1111 \\
\hline & Uniformly positive & 1.029 & 8.829 & 2.939 & 729 \\
& Mixed & 1.015 & 10.193 & 3.483 & 402 \\
& Uniformly negative & 0.907 & 9.205 & 2.388 & 2030 \\
\hline
\end{tabular}


Table II

Mean values of the four factors included in Model (1)

\begin{tabular}{|l|l|r|r|r|r|r|}
\hline Dimension & Subsample & Rm-Rf & SMB & HML & MOM & \multicolumn{1}{|c|}{ N } \\
\hline \multirow{4}{*}{ Community } & Uniformly positive & 8.803 & 3.699 & 2.970 & 11.316 & 1446 \\
& Mixed & 2.196 & 3.894 & 3.337 & 9.152 & 253 \\
& Uniformly negative & -1.120 & 3.388 & 0.702 & 10.747 & 701 \\
\hline \multirow{5}{*}{ Diversity } & Uniformly positive & 4.308 & 3.430 & 2.744 & 10.440 & 2797 \\
& Mixed & 1.062 & 4.455 & 3.162 & 8.616 & 519 \\
& Uniformly negative & 1.141 & 3.413 & 1.765 & 10.261 & 236 \\
\hline \multirow{5}{*}{ Environmentoyee } & Uniformly positive & 5.368 & 3.624 & 3.216 & 11.326 & 2076 \\
& Mixed & -1.144 & 3.406 & 1.131 & 10.498 & 671 \\
& Uniformly negative & 1.271 & 3.101 & 1.074 & 10.131 & 1036 \\
\hline \multirow{5}{*}{ Product } & Uniformly positive & 5.798 & 2.030 & 1.446 & 12.025 & 671 \\
& Mixed & 5.041 & 2.749 & 1.063 & 11.365 & 837 \\
& Uniformly negative & 5.720 & 3.509 & 3.134 & 10.825 & 1111 \\
\hline & Uniformly positive & 6.184 & 3.399 & 2.990 & 11.773 & 729 \\
& Mixed & 3.544 & 3.491 & 2.474 & 10.469 & 402 \\
& Uniformly negative & 3.220 & 3.573 & 2.209 & 10.104 & 2030 \\
\hline
\end{tabular}


Table III

Pooled OLS regression results: Estimated abnormal returns across subsamples

\begin{tabular}{|c|c|c|c|c|c|c|c|c|c|}
\hline Dimension & Subsample & alpha & Rm - I & & SMB & HML & MOM & F-statistic & Adj-Rsq \\
\hline \multirow{3}{*}{ Community } & Uniformly positive & $19.75 \%{ }_{(0.019)}^{* * *}$ & -0.0017 & $\begin{array}{l}* * * \\
(0.001)\end{array}$ & $-0.0013(0.001)$ & $-0.0016_{(0.001)}^{* *}$ & $-0.0032_{(0.001)}^{* * *}$ & $4.579^{* * *}$ & $0.98 \%$ \\
\hline & Mixed & $3.29 \%(0.041)$ & 0.0006 & $(0.001)$ & $0.0025(0.002)$ & $0.0016 \quad(0.002)$ & $0.0032(0.002)$ & $3.476^{\text {*** }}$ & $1.06 \%$ \\
\hline & Uniformly negative & $12.92 \%{ }_{(0.020)}^{* * *}$ & -0.0039 & $\begin{array}{l}\text { **** } \\
(0.001)\end{array}$ & $0.0003(0.001)$ & $\begin{array}{ll}0.0001 & (0.005) \\
\end{array}$ & $-0.0044_{(0.001)}^{* * *}$ & $10.828^{* * *}$ & $5.32 \%$ \\
\hline \multirow{3}{*}{ Diversity } & Uniformly positive & $14.48 \% \quad{ }_{(0.012)}^{* * *}$ & -0.0017 & $\begin{array}{l}\text { *** } \\
(0.000)\end{array}$ & $-0.0020_{(0.001)}^{* * *}$ & $-0.0006(0.001)$ & $-0.0024_{(0.001)}^{* * *}$ & $7.390^{\text {*** }}$ & $0.91 \%$ \\
\hline & Mixed & $5.83 \%{ }_{(0.024)}^{* *}$ & -0.0026 & $\begin{array}{l}\text { *** } \\
(0.001)\end{array}$ & 0.0012 (0.001) & $0.0004_{(0.001)}$ & $-0.0011(0.002)$ & $3.455^{\text {*** }}$ & $1.86 \%$ \\
\hline & Uniformly negative & $11.99 \%{ }_{(0.036)}^{* * *}$ & -0.0039 & $\begin{array}{l}\text { **** } \\
(0.001)\end{array}$ & $0.0040(0.003)$ & $-0.0025(0.002)$ & $-0.0015(0.002)$ & $3.021^{* *}$ & $3.33 \%$ \\
\hline \multirow{3}{*}{ Employee } & Uniformly positive & $14.85 \%{ }^{* * *}(0.015)$ & -0.0011 & $\begin{array}{l}\text { ** } \\
(0.000) \\
\end{array}$ & $-0.0025_{(0.001)}^{* * *}$ & $-0.0012(0.001)$ & $-0.0014_{(0.001)}^{* *}$ & $5.048^{\text {*** }}$ & $0.77 \%$ \\
\hline & Mixed & $\begin{aligned} & 9.42 \% \begin{array}{l}* * * \\
(0.021)\end{array} \\
& * * *\end{aligned}$ & -0.0049 & $\begin{array}{l}* * * \\
(0.001) \\
* * *\end{array}$ & $-0.0025(0.002)$ & $\frac{0.0013}{(0.002)}$ & $-0.0024^{*}(0.001)$ & $13.167^{* * *}$ & $6.77 \%$ \\
\hline & Uniformly negative & $10.73 \%$ (0.016) & -0.0038 & $\begin{array}{l}* * * \\
(0.001) \\
\end{array}$ & $0.0005_{(0.001)}$ & 0.0019 (0.001) & $-0.0018^{*}(0.001)$ & $14.143^{* * *}$ & $4.83 \%$ \\
\hline \multirow{3}{*}{ Environment } & Uniformly positive & $16.08 \%{ }^{* * *}(0.022)$ & -0.0022 & $\begin{array}{l}\text { *** } \\
(0.001)\end{array}$ & $-0.0013(0.001)$ & $-0.0001(0.011)$ & $-0.0030 \begin{array}{l}* * * \\
(0.001)\end{array}$ & $3.857^{\text {*** }}$ & $1.68 \%$ \\
\hline & Mixed & $16.56 \% \begin{array}{l}\text { **** } \\
(0.017) \\
\end{array}$ & -0.0018 & $\begin{array}{l}* * * \\
(0.000) \\
\end{array}$ & $-0.0026_{(0.001)}^{* *}$ & $0.0002(0.001)$ & $-0.0035_{(0.001)}^{* * *}$ & $5.982^{\text {*** }}$ & $2.33 \%$ \\
\hline & Uniformly negative & $18.44 \% \begin{array}{l}\text { *** } \\
(0.017)\end{array}$ & -0.0026 & $\begin{array}{l}* * * \\
(0.001)\end{array}$ & $-0.0011(0.001)$ & $-0.0014_{(0.001)}^{* *}$ & $-0.0053_{(0.001)}^{* * *}$ & $11.771^{* * *}$ & $3.74 \%$ \\
\hline \multirow{3}{*}{ Product } & Uniformly positive & $19.80 \% \begin{array}{l}\text { *** } \\
(0.026) \\
\end{array}$ & -0.0026 & $\begin{array}{l}* * * \\
(0.022) \\
* *\end{array}$ & $-0.0042_{(0.001)}^{* * *}$ & $\begin{array}{ll}-0.0027 & * * * \\
(0.001) \\
\end{array}$ & $-0.0035_{(0.001)}^{* * *}$ & $7.004^{\text {*** }}$ & $3.19 \%$ \\
\hline & Mixed & $6.36 \%{ }^{*}(0.034)$ & 0.0001 & $\begin{array}{l}* * * \\
(0.000)\end{array}$ & $0.0034(0.170)$ & $0.0031_{(0.002)}^{*}$ & $0.0023(0.002)$ & $3.009^{\text {** }}$ & $0.21 \%$ \\
\hline & Uniformly negative & $12.12 \%{ }_{(0.012)}^{* * *}$ & -0.0023 & $\begin{array}{l}\text { *** } \\
(0.001)\end{array}$ & $0.0011 \quad(0.001)$ & $0.0002(0.001)$ & $-0.0015_{(0.001)}^{* *}$ & $11.339^{* * *}$ & $2.00 \%$ \\
\hline
\end{tabular}

Note: $*$, ** and $* * *$ denote significance at the $90 \%, 95 \%$ and $99 \%$ levels, respectively. 
Table IV

Comparing es timated abnormal returns across subsamples

\begin{tabular}{|c|c|c|}
\hline Dimension & Subsamples compared & net alpha \\
\hline \multirow{3}{*}{ Community } & Uniformly positive v Mixed & $19.39 \%{ }_{(0.054)}^{* * *}$ \\
\hline & Uniformly negative $\mathrm{v}$ Mixed & $11.25 \%$ \\
\hline & Uniformly positive v Uniformly negative & $7.90 \%{ }_{(0.036)}^{* *}$ \\
\hline \multirow{3}{*}{ Diversity } & Uniformly positive v Mixed & $11.08 \%{ }_{(0.040)}^{* * *}$ \\
\hline & Uniformly negative $\mathrm{v}$ Mixed & $8.53 \%(0.062)$ \\
\hline & Uniformly positive v Uniformly negative & $2.46 \%(0.056)$ \\
\hline \multirow{3}{*}{ Employee } & Uniformly positive v Mixed & 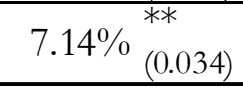 \\
\hline & Uniformly negative $\mathrm{v}$ Mixed & $1.43 \%(0.041)$ \\
\hline & Uniformly positive $\mathrm{v}$ Uniformly negative & $5.77 \%{ }_{(0.029)}^{*}$ \\
\hline \multirow{3}{*}{ Environment } & Uniformly positive v Mixed & $0.23 \%(0.042)$ \\
\hline & Uniformly negative $\mathrm{v}$ Mixed & $3.49 \%(0.036)$ \\
\hline & Uniformly positive v Uniformly negative & $-3.36 \%(0.043)$ \\
\hline \multirow{3}{*}{ Product } & Uniformly positive v Mixed & $20.03 \%{ }_{(0.060)}^{* * *}$ \\
\hline & Uniformly negative $\mathrm{v}$ Mixed & $8.42 \%(0.046)$ \\
\hline & Uniformly positive $\mathrm{v}$ Uniformly negative & $11.57 \%{ }_{(0.040)}^{* * *}$ \\
\hline
\end{tabular}

Note: $*{ }^{* *}$ and ${ }^{* * *}$ denote significance at the $90 \%, 95 \%$ and $99 \%$ levels, respectively. 
Table V

Comparing estimated abnormal returns across subsamples drawn according to aggregate CSP

\begin{tabular}{|l|l|c|}
\hline Dimension & Subsamples compared & net alpha \\
\hline \multirow{4}{*}{ Community } & First tertile v Second tertile & $-2.76 \%_{(0.021)}$ \\
\cline { 2 - 3 } & Second tertile v Third tertile & $1.43 \%_{(0.019)}$ \\
\cline { 2 - 3 } & First tertile v Third tertile & $-1.12 \%_{(0.018)}$ \\
\hline \multirow{5}{*}{ Employee } & First tertile v Second tertile & $0.34 \%_{(0.017)}$ \\
\cline { 2 - 3 } & Second tertile v Third tertile & $-1.24 \%_{(0.023)}$ \\
\cline { 2 - 3 } & First tertile v Third tertile & $-0.68 \%_{(0.022)}$ \\
\cline { 2 - 3 } & First tertile v Second tertile & $-0.37 \%_{(0.021)}$ \\
\cline { 2 - 3 } & Second tertile v Third tertile & $-1.22 \%_{(0.014)}$ \\
\cline { 2 - 3 } & First tertile v Third tertile & $-2.32 \%_{(0.014)}$ \\
\hline \multirow{5}{*}{ Environment } & First tertile v Second tertile & $-1.15 \%_{(0.021)}$ \\
\cline { 2 - 3 } & Second tertile v Third tertile & $-1.31 \%_{(0.019)}$ \\
\cline { 2 - 3 } & First tertile v Third tertile & $-2.34 \%_{(0.024)}$ \\
\hline \multirow{5}{*}{ Product } & First tertile v Second tertile & $-3.41 \%_{(0.020)}^{*}$ \\
\cline { 2 - 3 } & Second tertile v Third tertile & $3.29 \%_{(0.017)}$ \\
\cline { 2 - 3 } & First tertile v Third tertile & $0.45 \%_{(0.016)}$ \\
\hline
\end{tabular}

Note: $*$ and $* *$ denote significance at the $90 \%$ and $95 \%$ levels, respectively. 